\title{
Rancang Bangun Smart Chip Audio Organic Growth System sebagai Input Device Pembukaan Stomata pada Pemupukan Daun Tanaman Perkebunan
}

\author{
Nur Kadarisman, ${ }^{1}$ Wipsar Sunu Brams Dwandaru, ${ }^{1, *}$ dan Purwanti Widhy Hastuti ${ }^{2}$ \\ ${ }^{1}$ Jurusan Pendidikan Fisika, Fakultas Matematika dan Ilmu Pengetahuan Alam, \\ Universitas Negeri Yogyakarta, Jl. Colombo No.1 Yogyakarta 55281 \\ ${ }^{2}$ Jurusan Pendidikan IPA, Fakultas Matematika dan Ilmu Pengetahuan Alam, \\ Universitas Negeri Yogyakarta, Jl. Colombo No.1 Yogyakarta 55281
}

\begin{abstract}
Intisari
Aplikasi teknologi gelombang akustik dalam bidang pertanian dapat digunakan untuk meningkatkan ketahanan pangan suatu masyarakat. Rekayasa dan modifikasi teknologi audio, yakni audio organic growth system (AOGS), yang dipadukan dengan pemupukan daun (foliar) dan optimasi variabel intensitas audio telah digunakan untuk meningkatkan produktivitas dan kualitas tanaman perkebunan. Kegunaan utama sistem AOGS adalah sebagai input device dalam pembukaan stomata daun tanaman perkebunan. Kendala utama dalam penerapan AOGS di lapangan adalah perangkat elektronik yang digunakan belum praktis dan belum compatible. Selain itu, instrumen AOGS yang terdiri dari audio player dan speaker ternyata cukup berat. Dalam penelitian ini, telah dihasilkan instrumentasi smart chip AOGS (SC-AOGS) dengan komponen TDA2003 sebagai penguat audio, WT5001 sebagai penyimpan dan pemutar audio, ATMega328 kecepatan $16 \mathrm{MHz}$ sebagai prosesor, speaker sebagai sumber ouput dari suara, dan LCD matrik ukuran $16 \times 2$ yang menghasilkan display sumber frekuensi output yang dipaparkan. Instrumen SC-AOGS ini juga dilengkapi dengan pengaturan volume suara. Lebih jauh, instrumen SC-AOGS ini cukup praktis dan compatible sehingga dapat mengatasi kendala pada instrumen AOGS
\end{abstract}

\begin{abstract}
The application of acoustic wave technology for agriculture purposes may be used to strengthen the food persistency in the society. The creation and modification of audio technology, which is in this case, the audio organic growth system (AOGS) combined with foliar fertilization and audio intensity variable optimization has been applied to increase the quality and productivity of plantation crops. The AOGS system is mainly used as an input device in the leaf stomata opening of plantation crops. However, the main obstacle in the application of AOGS is the electronic devices which are not practical and compatible. Moreover, the AOGS instrument which consists of an audio player and a speaker turns out to be quite heavy. Hence, in this research, a smart chip AOGS (SC-AOGS) has been produced equipped with components of TDA2003 as an audio amplifier, WT5001 as a storage and audio player, ATMega328 $16 \mathrm{MHz}$ as a processor, a speaker as an output source of the sound, and a matrix LCD with dimension of $16 \times 2$ that produces output frequency source display. Moreover, the SC-AOGS instrument is also equipped with sound volume setting. The SC-AOGS instrument is quite easy to use and compatible, hence may overcome the problem of the AOGS system.
\end{abstract}

KATA KUNCI: smart chip audio organic growth system, leaf fertilization, leaf stomata opening, plantation crops

\section{PENDAHULUAN}

Salah satu penelitian unggulan yang sedang dikembangkan melalui kegiatan penelitian payung di Laboratorium Fisika Akustik FMIPA UNY adalah pemanfaatan audio organic growth system (AOGS) yang berbasis frekuensi binatang alamiah lokal untuk peningkatan produktivitas tanaman $[1,2]$. Salah satu hasil penelitian sebelumnya [2] terkait pemanfaatan teknologi audio pada tanaman kentang (Solanum tuberosum L.) menunjukkan adanya peningkatan kualitas dan produkti-

\footnotetext{
*E-MAIL: wipsarian@uny.ac. id
}

vitas hasil panen tanaman kentang.

Namun demikian, permasalahan yang masih mengganggu dalam penggunaan AOGS adalah kurang praktis dalam pelaksanaannya dan perangkat elektronik yang masih cukup mahal untuk kalangan petani. Hal ini tentu saja harus dapat diatasi sehingga menjadi lebih sederhana, murah, dan praktis digunakan di lahan pertanian. Lebih jauh lagi, kendala utama dalam penerapan AOGS di lapangan pada penelitian sebelumnya [2] adalah perangkat elektronik yang digunakan belum praktis dan compatible. Secara teknis, petani harus memasang dan memindahkan perangkat audio yang terdiri dari audio player dan speaker yang cukup berat. Kendala ini perlu ditindaklanjuti dengan melibatkan teknologi terpadu, yakni penggunaan gelombang akustik [3-6] untuk pembukaan stomata 


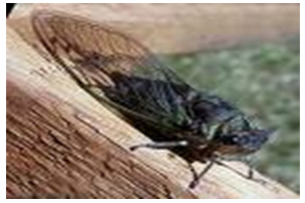

(a) garengpung

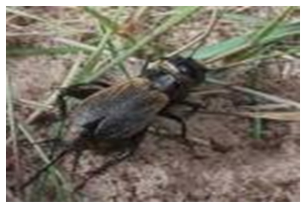

(c) jangkrik

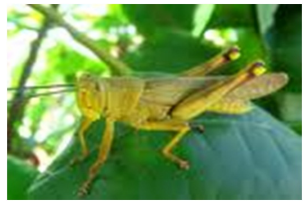

(b) belalang

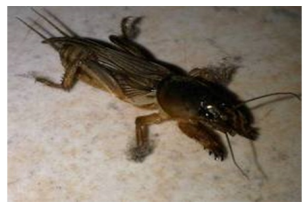

(d) orong-orong
Gambar 1: Kearifan lokal binatang alamiah yang memiliki peak frekuensi 2000-6000 Hz.

daun [7-9] dan pemberian pupuk [5], sehingga dapat memberikan hasil yang lebih optimal. Dalam hal ini, telah dikembangkan sebuah perangkat teknologi gelombang akustik yang kecil dan praktis, tetapi memiliki kapasitas tinggi, yaitu: smart chip AOGS (SC-AOGS). Di samping itu, diharapkan SC-AOGS dapat disebarluaskan terutama kepada para petani sebagai teknologi tepat guna dan ramah lingkungan.

Secara umum, penelitian ini bertujuan untuk melakukan perekayasaan dan modifikasi SC-AOGS terpadu antara pemupukan daun (foliar) dengan optimasi variabel intensitas audio [10], waktu papar, dan spesifikasi frekuensi resonansi binatang khas indonesia $[1,11]$ untuk meningkatkan produktivitas dan kualitas tanaman pangan [6]. Hal ini sejalan dengan upaya peningkatan ketahanan pangan, terutama tanaman perkebunan yang memiliki potensi tinggi sebagai komoditas ekspor. Secara khusus, tujuan penelitian ini adalah melakukan rancang bangun perangkat teknologi gelombang akustik yang kecil dan praktis tetapi memiliki kapasitas tinggi, yakni SCAOGS, untuk pemupukan daun bersama yang memiliki karakteristik khusus untuk tanaman pangan tertentu.

\section{METODE PENELITIAN}

Langkah-langkah dalam penelitian ini dapat dijelaskan sebagai berikut:

1. Merekam dan menganalisis frekuensi asli binatang alami di Indonesia yaitu garengpung, belalang, jangkrik, dan orong-orong (Gambar 1).

2. Suara yang sudah direkam dapat dianalisis secara langsung menggunakan aplikasi Spectrum Analysis yang tersedia dalam program Sound Forge 6.0. Hasil dari analisis ini adalah spektrum sinyal. Dari spektrum tersebut, diperoleh nilai frekuensi dengan amplitudo paling tinggi (prominent frequency), frekuensi harmonik, dan frekuensi penyusun di sekitar frekuensi tertinggi, serta nilai amplitudo masing-masing frekuensi.

3. Bunyi disintesis dari suara asli menjadi suara dengan frekuensi yang bervariasi. Sedangkan, amplitudo dan

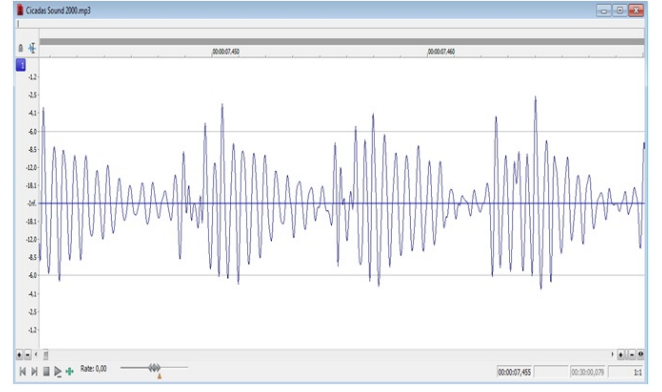

(a)

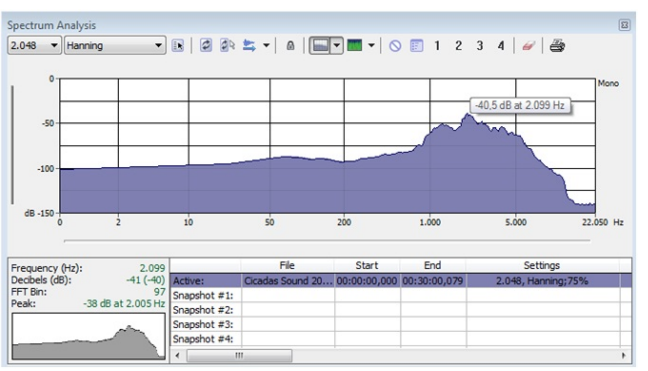

(b)

Gambar 2: Spektrum analisis suara garengpung asli (a) yang disintesis menjadi peak frekuensi $2000 \mathrm{~Hz}$ (b).

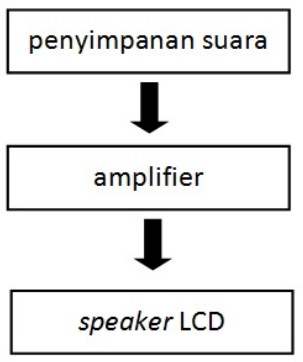

Gambar 3: Diagram rancangan elektronik SC-AOGS.

rasio amplitudo masing-masing frekuensi sudah terprogram secara otomatis pada software Sound Forge 6.0. Salah satu contoh hasil analisis frekuensi bunyi menggunakan program Sound Forge 6.0, dan setelah disintesis didapatkan hasil keluaran seperti grafik pada Gambar 2. Hasil analisis spektrum tersebut memiliki frekuensi $2000 \mathrm{~Hz}$. Spektrum ini digunakan untuk menganalisis apakah frekuensi yang digunakan tepat atau mendekati dengan frekuensi yang diharapkan.

4. Bunyi yang sudah disintesis peak frekuensinya dengan variasi frekuensi 3000, 3500, 4000, 4500, dan $5000 \mathrm{~Hz}$ dimasukkan dalam microchip sebagai komponen utama dari pembuatan SC-AOGS. Rangkaian elektronik SCAOGS secara diagramatik dapat dilihat pada Gambar 3.

Dapat diamati dari Gambar 3 bahwa rangkaian diagram SC-AOGS terdiri dari penyimpan bunyi atau suara, amplifier, dan speaker LCD. Penyimpan suara dan amplifier ini akan dibungkus dalam kotak yang sama, sedangkan speaker 


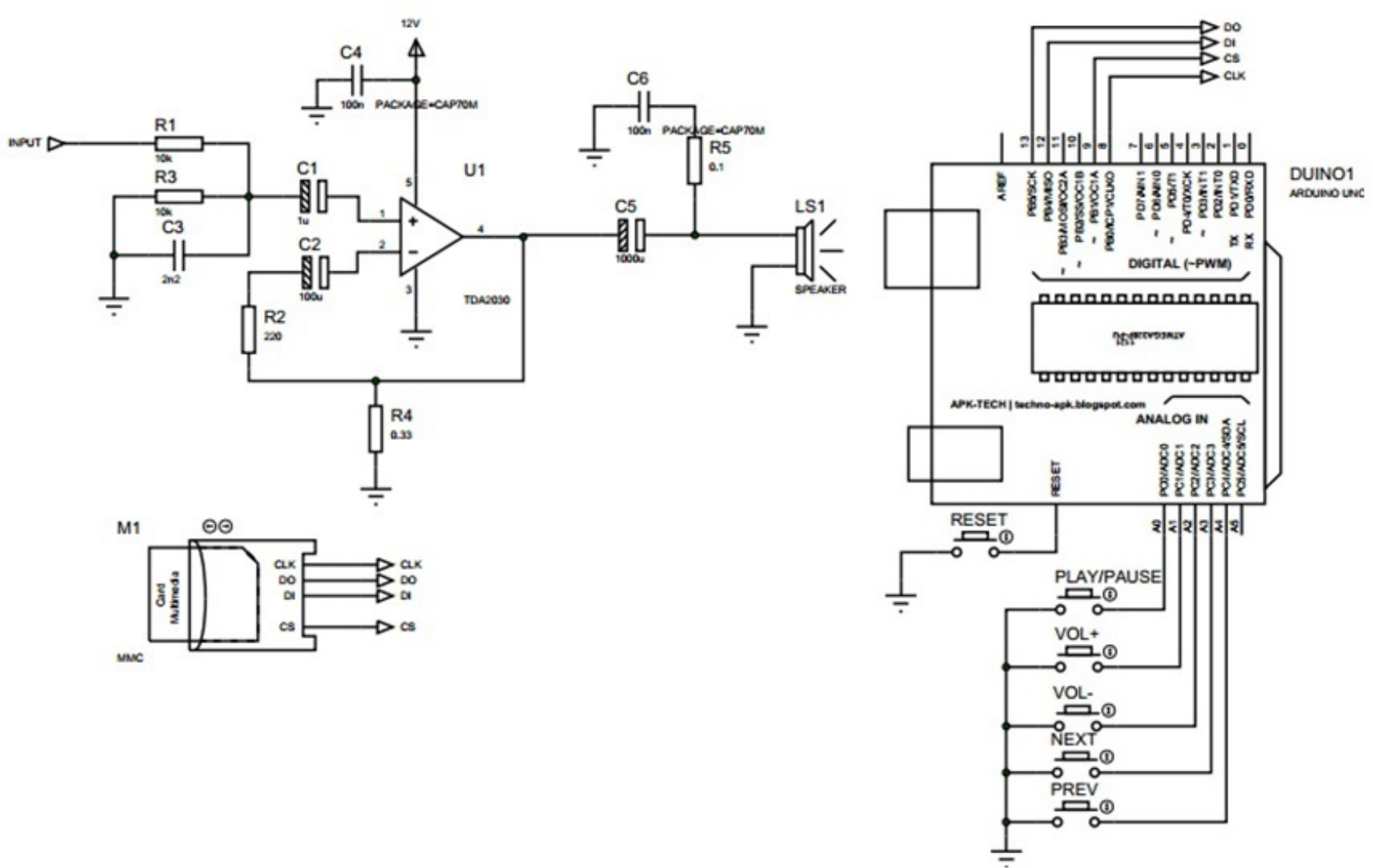

Gambar 4: Skema rangkaian elektronik SC-AOGS.

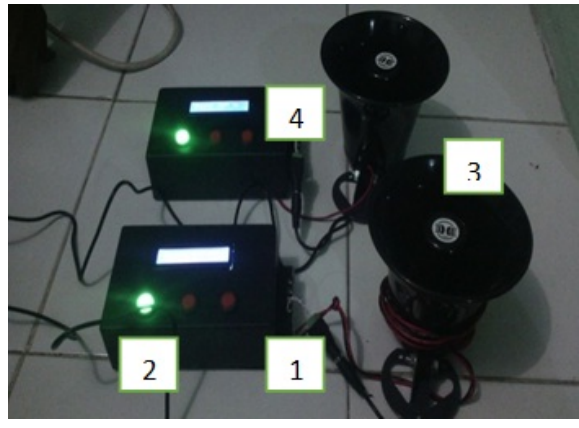

Gambar 5: Instrumentasi SC-AOGS.

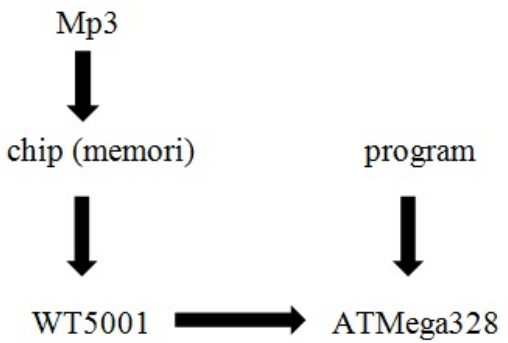

Gambar 6: Diagram kerja alat penyimpan suara. dibuat terpisah dari sistem. Berbagai komponen yang dibutuhkan untuk membangun alat SC-AOGS, yakni: speaker, kabel penghubung, TDA2003, WT5001, ATMega328 dengan kecepatan $16 \mathrm{MHz}$, LCD matrik ukuran $6 \times 2$, dan software Arduino Uno. Skema rangkaian elektronik SC-AOGS dapat dilihat pada Gambar 4. Skema elektonik ini merupakan hasil pengejawantahan diagram rancangan pada Gambar 3.

\section{HASIL DAN PEMBAHASAN}

Foto sistem SC-AOGS yang telah dibangun dapat dilihat pada Gambar 5, instrumentasi SC-AOGS terdiri dari se- buah kotak hitam (1) yang di dalamnya berisi alat penyimpan suara dan amplifier. Kotak hitam ini memiliki layar penunjuk frekuensi berupa LCD matriks $6 \times 2$ (4). Instrumentasi ini dilengkapi pula dengan tombol pemilih frekuensi dan pengatur volume frekuensi yang dipilih (2). Kotak hitam ini selanjutnya dihubungkan dengan speaker (3).

Dalam kotak penyimpan suara ini terdapat beberapa komponen yang salah satunya berfungsi sebagai tempat untuk menyimpan chip berupa microSD yang telah terisi sumber bunyi garengpung dengan frekuensi (dalam Hz) 3000, 3500, 4000, 4500, dan 5000. Komponen yang berfungsi sebagai penyimpan suara untuk SC-AOGS dengan sumber bunyi garengpung ini yaitu WT5001 yang nantinya ketika alat mulai dioperasikan, komponen ATMega328 yang telah terisi pro- 
WT5001 amplifier speaker

Gambar 7: Diagram kerja amplifier.

gram yang berfungsi sebagai prosesor akan memerintahkan WT5001 untuk memutar sumber bunyi garengpung.

Komponen-komponen elektronik yang terdapat pada penyimpan suara adalah ATMega328 kecepatan $16 \mathrm{MHz}$, chip (memori), dan WT5001. Diagram prosedur kerja penyimpan suara menggunakan ketiga komponen di atas dapat dilihat pada Gambar 6.

Program yang telah dibuat, di-flasing (di-upload) menggunakan software Arduino Uno ke komponen ATMega328. Sumber bunyi garengpung dengan lima macam variasi frekuensi disimpan pada chip dan dipasangkan pada komponen WT5001 yang kemudian dirangkai dengan komponen ATMega328. Cara penyimpanan suara pada chip dapat diberikan sebagai berikut:

1. Memasukkan chip yang berupa microSD dalam computer (PC),

2. menyimpan lima macam frekuensi suara garengpung dalam bentuk Mp3 pada folder,

3. mem-flasing folder dalam chip,

4. chip kemudian dilepaskan dari PC dan dipasangkan pada komponen WT5001.

Selanjutnya, untuk mem-flasing program pada ATMega328 dapat dilakukan dengan cara sebagai berikut:

1. Membuat program pada software Arduino Uno,

2. mem-flasing program yang telah dibuat pada ATMega328 dengan kabel penghubung.

3. setelah program telah selesai di-flasing, kabel penghubung dilepaskan dari PC dan ATMega328 siap dirangkai dengan amplifier dan speaker.

Amplifier berfungsi untuk menguatkan sinyal atau frekuensi yang diaktifkan. Berbagai komponen yang diperlukan untuk amplifier ini adalah TDA2003, resistor $220 \Omega$ (1 buah), resistor $330 \Omega$ (1 buah), resistor $100 \Omega$ (1 buah), resistor $10 \mathrm{k} \Omega(2$ buah), kapasitor $100 \mathrm{nF}$, kapasitor $1 \mathrm{~F}$, kapasitor $100 \mu \mathrm{F}$, kapasitor $1000 \mu \mathrm{F}$, dan kapasitor 2n2. Sedangkan prosedur kerja amplifier dapat dilihat pada Gambar 7.

Sumber bunyi yang diputar melalui komponen WT5001 diperkuat audionya oleh amplifier dengan komponen utamanya, yaitu TDA2003. Setelah audio-nya diperkuat, hasilnya di-output-kan melalui speaker. Skema rangkaian penguat audio-nya dapat diamati pada Gambar 8.

Sumber bunyi yang diputar akan di-output melalui speaker. Speaker yang digunakan memiliki daya 12 watt. Ilustrasi speakernya dapat diamati pada Gambar 9.

Secara keseluruhan, fungsi dari masing-masing komponen SC-AOGS dapat diberikan sebagai berikut:

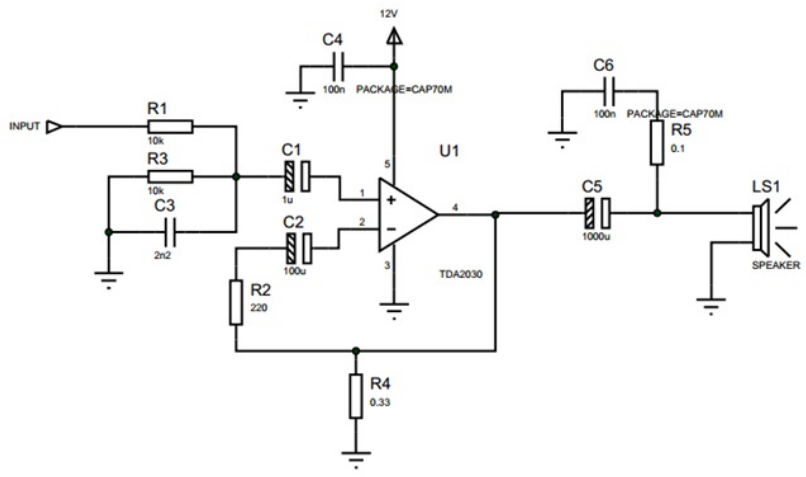

Gambar 8: Skema rangkaian penguat audio.

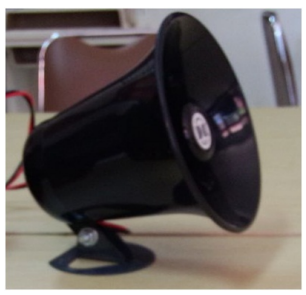

Gambar 9: Speaker.

1. TDA2003 sebagai penguat audio.

2. WT5001 sebagai penyimpan dan pemutar audio.

3. ATMega328 kecepatan $16 \mathrm{MHz}$ sebagai prosesor.

4. Speaker sebagai peng-ouput dari suara.

5. LCD matrik ukuran $16 \times 2$ sebagai pen-display sumber frekuensi yang sedang diputar.

Diagram cara kerja secara keseluruhan dari sistem SC-AOGS dapat dilihat pada Gambar 10. Prinsip kerja alat SC-AOGS secara keseluruhan dapat dijelaskan sebagai berikut. File yang berupa format Mp3 yang berbunyi suara garengpung disimpan dalam chip yang berupa microSD. Selanjutnya,

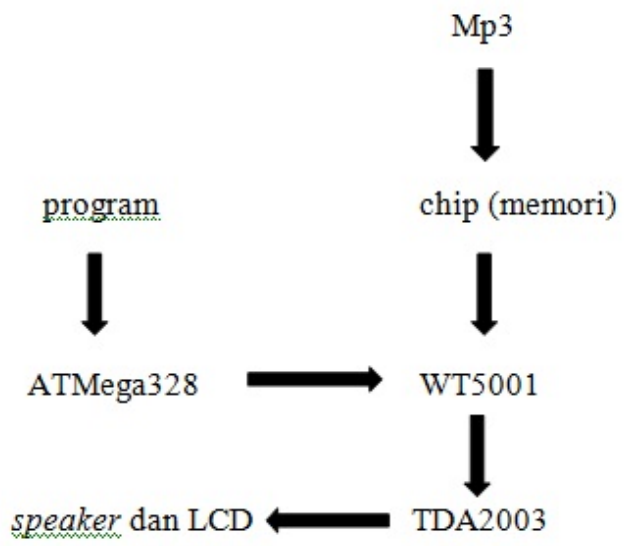

Gambar 10: Diagram kerja SC-AOGS. 


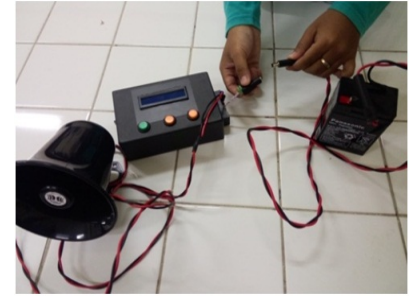

(a)

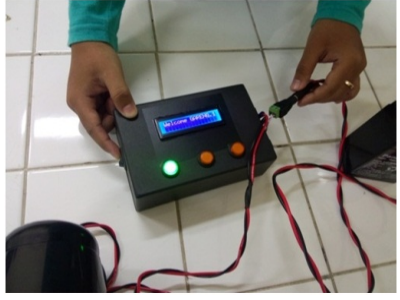

(b)

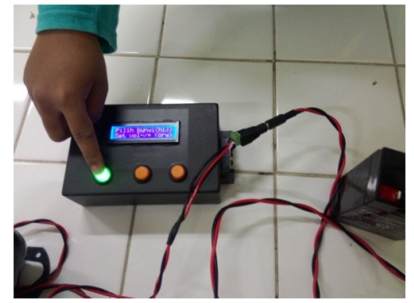

(c)

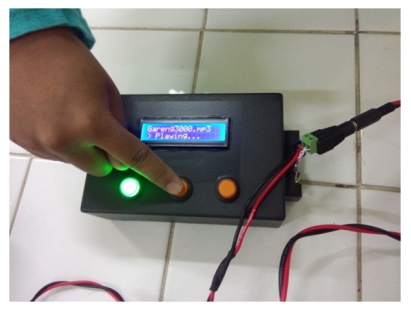

(d)

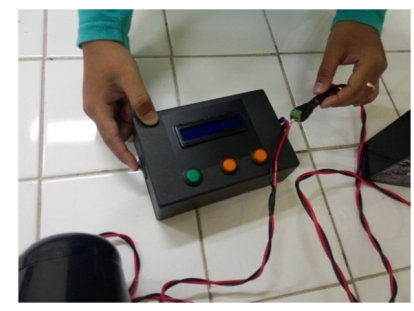

(e)

Gambar 11: Pengoperasian peralatan, (a) menghubungkan SC-AOGS dengan sumber tegangan aki, (b) tekan tombol ON/OFF, (c) tekan tombol warna hijau untuk memilih frekuensi suara garengpung dan mulai pemaparan, (d) tekan tombol warna kuning untuk mengubah volume, (e) tekan tombol OFF untuk mematikan alat.

microSD ini dipasangkan pada WT5001. Program yang telah dibuat dengan software Arduino Uno di-flasing pada Arduino Uno yang terdapat IC ATMega328. Ketika alat mulai dioperasikan, ATMega328 yang berfungsi sebagai prosesor akan memerintahkan WT5001 memanggil file dengan format Mp3 tadi untuk diputar dan bunyi yang dihasilkan diperkuat audionya oleh TDA2003. Bunyi yang audio-nya telah diperkuat tadi, akan dikeluarkan melalui speaker. LCD matriks akan men-display sumber bunyi frekuensi yang sedang diputar.

Cara mengoperasikan alat SC-AOGS dapat dijelaskan sebagai berikut:

1. Menghubungkan alat dengan sumber tegangan,

2. menghidupkan alat dengan menekan saklar tombol $\mathrm{ON} / \mathrm{OFF}$,

3. menekan tombol warna hijau untuk memulai membunyikan suara garengpong dengan frekuensi yang telah ditentukan,

4. mengatur tombol volume sesuai dengan volume yang dibutuhkan. Pada saat pertama kali alat dioperasikan, secara otomatis alat berada pada volume yang di tengah-tengah,

5. setelah alat selesai digunakan, untuk mematikan alat ditekan tombol OFF.

Praktek cara pengoperasian alat SC-AOGS dapat diamati dalam ilustrasi sebagai berikut:

1. Menghubungkan alat dengan sumber tegangan accumulator (aki) (Gambar 11(a)).
2. menekan tombol ON/OFF pada sisi alat sehingga lampu hijau menyala (Gambar 11(b)).

3. memilih frekuensi suara garengpong yang ditentukan dengan menekan tombol hijau.

4. menekan lagi tombol hijau untuk memulai (play) (Gambar 11(c)).

5. mengatur tombol volume sesuai dengan volume yang dibutuhkan, tombol warna kuning di sisi kanan untuk menaikkan volume dan di sisi kiri untuk mengurangi volume (Gambar 11(d)).

6. setelah alat selesai digunakan, untuk mematikan alat, tombol OFF ditekan hingga lampu hijau mati (Gambar 11(e)).

\section{SIMPULAN}

Telah dihasilkan instrumentasi SC-AOGS yang terdiri dari sistem penyimpan suara, amplifier, dan juga speaker. Penyimpan suara dan amplifier dipadukan dalam sebuah kotak hitam yang dilengkapi dengan layar LCD matriks $6 \times 2$, pemilih bunyi, dan pengatur volume. Instrumen SC-AOGS ini dapat diaplikasikan untuk memaparkan suara pada tanaman perkebunan.

\section{Ucapan Terima Kasih}

Penelitian ini telah didanai oleh Islamic Development Bank (IDB) melalui DIPA Direktorat Penelitian Pengabdian Kepada Masyarakat dengan Nomor DIPA: 023.04.1.673453/2015, tanggal 14 November 2014, DIPA revisi 01 tanggal 3 Maret 
[1] S. Ningsih, A. Purwanto, dan Ratnawati, Pengaruh Frekuensi Akustik Suara Serangga "Kinjengtangis" terhadap Lebar Bukaan Stomata Daun dan Pertumbuhan Kacang Tanah, Skripsi S1, FMIPA Universitas Negeri Yogyakarta, Yogyakarta, Indonesia 2007.

[2] N. Kadarisman, Peningkatan Laju Pertumbuhan dan Produktivitas Tanaman Kentang melalui Spesifikasi Variabel Fisis Gelombang Akustik pada Pemupukan Daun, Laporan Penelitian, Universitas Negeri Yogyakarta, Yogyakarta, Indonesia, 2010.

[3] A. Coghlan, Good Vibrations Give Plants Excitations (New Scientist, 28 May, p. 10, 1994).

[4] K.H. Purwadaria, Sonic Bloom Resonance, a Friend in Silence, Suara Merdeka, Juni 15 (2002)

[5] P. Tompkins and C. Bird, Secrets of the Soil (Harper \& Row, 2001).
[6] S. Latifah, Pertumbuhan Dimensi Tegakan Pangan (Durio Zibethinus Murr) bersama Teknologi Sonic Bloom, Universitas Sumatra Utara, Medan, 2003.

[7] A.G. Kartasaputra, Pengantar Anatomi Tumbuh-Tumbuhan, tentang Sel, dan Jaringan (Bina Aksara, Jakarta, 1998).

[8] B. Lakitan, Dasar-dasar Fisiologi Tumbuhan (Raja Grafindo Persada, 1993).

[9] A.R. Loveless, Prinsip-prinsip Biologi Tumbuhan untuk Daerah Tropik (Gramedia Pustaka Utama, 2011).

[10] A. Hirose, and K.E. Lonngren, Introduction to Wave Phenomena (John Willey \& Sons, 1985)

[11] T. Eisner, and E.O. Wilson, The Insect Scientific American (W. H. Freeman and Company, 1977). 